\title{
BILATERAL LOBAR TRANSPLANTATION WITH THE SPLIT LUNG TECHNIQUE
}

Omeros Artemiou, MD, ${ }^{\mathrm{a}}$ Tudor Birsan, MD, ${ }^{\mathrm{a}}$ Shahrokh Taghavi, MD, ${ }^{\mathrm{a}}$ Irmgard Eichler, MD, ${ }^{\mathrm{b}}$ Wilfried Wisser, MD, ${ }^{\mathrm{a}}$ Ernst Wolner, MD, ${ }^{\mathrm{a}}$ and Walter Klepetko, MD, ${ }^{\mathrm{a}}$ Vienna, Austria

The shortage of donor lungs suitable for children and small adult patients has led to the development of new operative techniques. Donor lungs can be downsized either by peripheral segmental resections (tailoring) ${ }^{1}$ or by transplantation of single cadaveric lobes. ${ }^{2}$ The ultimate solution for optimal use of donor lungs is the split-lung technique (ie, bipartitioning of a left donor lung and bilateral transplantation of the two lobes), which was described by Couetil and associates. ${ }^{3}$ However, this method and its feasibility have not been confirmed by any other center. We therefore report our initial experience with this technique.

Clinical summary. A 14-year-old girl (height $143 \mathrm{~cm}$, weight $23 \mathrm{~kg}$ ) with end-stage cystic fibrosis was listed for bilateral lung transplantation in December 1997. Only 10 days later she had a spontaneous pneumothorax and was admitted to the hospital. With chest drainage, the patient's condition improved initially, but a subsequent pulmonary infection led to respiratory deterioration that necessitated intubation and continuous mechanical ventilation. A special urgency request was forwarded to the Eurotransplant Foundation. A continuous rise of carbon dioxide tension and decreasing oxygenation despite maximal ventilation indicated the need for extracorporeal membrane oxygenation. Two days later, the left lung of a significantly larger donor (height $167 \mathrm{~cm}$, weight $60 \mathrm{~kg}$ ) became available. In view of the patient's critical condition and the limited chances to receive a size-compatible double lung block in time, the possibility for bipartitioning of this left lung was investigated.

The recipient's total lung capacity (TLC) and the donor's left lung capacity (LLC, calculated as $45 \%$ of the predicted TLC) were used to estimate size matching. The calculation of the predicted donor TLC was based on the standardization of the European Respiratory Society ${ }^{4}$ TLC $(\mathrm{L})=6.60 \times$ height (m) -5.79 for a female patient. The donor's LLC was $2.36 \mathrm{~L}$ and the recipient's TLC was $2.54 \mathrm{~L}$, resulting in a ratio of 0.92 , a value considered to be optimal for the procedure.

Donor lungs were harvested in the usual way with epoprostenol and modified Euro-Collins solution combined with topical cooling. The recipient operation was performed

From the Departments of Cardiothoracic Surgery and Pediatrics, ${ }^{\mathrm{b}}$ University of Vienna, Austria.

Received for publication March 9, 1999; accepted for publication March 23, 1999.

Address for reprints: W. Klepetko MD, Associate Professor of Surgery, Department of Cardiothoracic Surgery, University of Vienna, Währinger Strasse 18-20, A-1090 Vienna, Austria.

J Thorac Cardiovasc Surg 1999;118:369-70

Copyright (C) 1999 by Mosby, Inc.

$0022-5223 / 99 \$ 8.00+0 \quad \mathbf{1 2 / 5 4 / 9 8 7 3 0}$

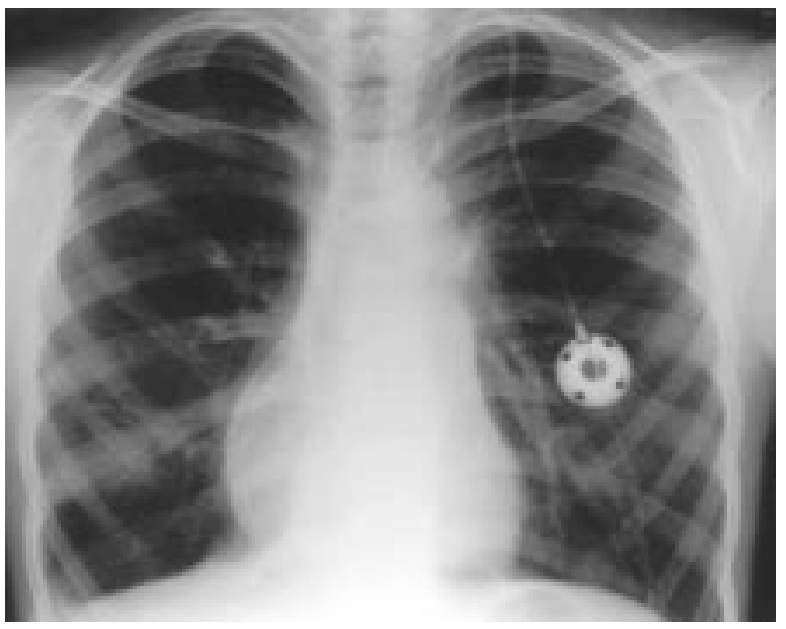

Fig 1. Chest radiograph 3 months after transplantation showing an ideal adaption of the lobes.

via bilateral transsternal thoracotomy. Because of severe hemodynamic instability, the patient was supported by normothermic cardiopulmonary bypass. Both lungs were excised in the typical way except that the arterial pedicles were left longer and the right upper lobe bronchus was stapled at its origin, leaving the right main bronchus and bronchus intermedius intact.

The splitting of the left donor lung and the implantation of the resulting two lobes were performed as described by Couetil and colleagues. ${ }^{3}$ Dissection of the completely developed fissure together with transection of the pulmonary artery in an oblique way, thus separating upper and lower lobe arterial branches, was followed by transection of the orifices of the upper and lower lobe bronchi. The main stem of the pulmonary artery was then shortened to the origin of the first segmental artery branch and closed with a continuous Prolene suture (Ethicon, Inc, Somerville, NJ). The upper lobe was brought into the right thoracic cavity after 180 degrees' rotation in the vertical axis.

The anastomoses were constructed end to end in the following sequence: upper lobe donor bronchus to bronchus intermedius of the recipient (running 5-0 PDS suture; Ethicon); distal end of upper lobe donor pulmonary artery to recipient right pulmonary artery; donor upper lobe vein to atrial cuff of recipient. The implantation of the left lobe was carried out in the usual way. Ischemic time was 300 minutes (right lobe) and 350 minutes (left lobe). The total cardiopulmonary bypass time was 166 minutes.

Although no surgical problems such as bleeding, prolonged air leak, or bronchial stenosis were observed, the postopera- 


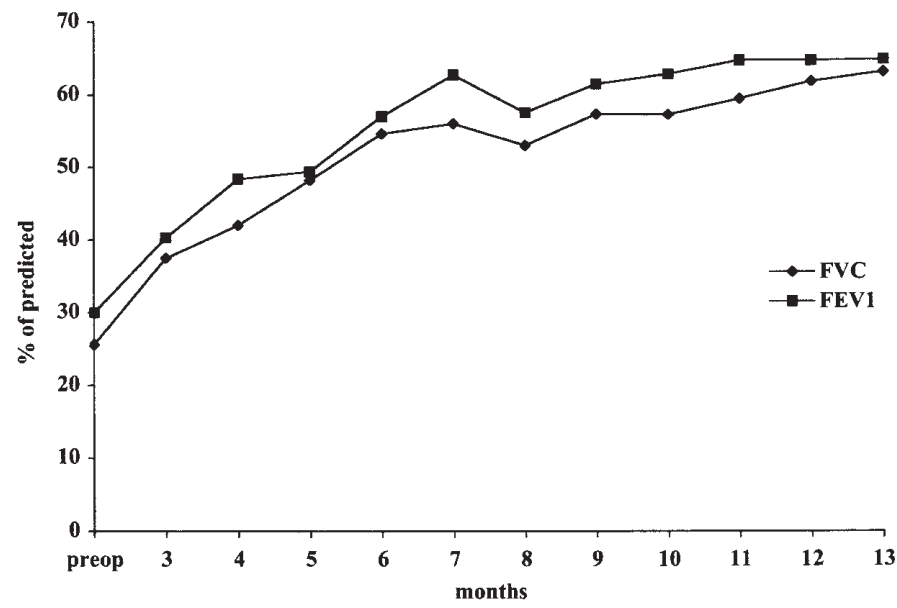

Fig 2. Course of lung function.

tive course was complicated by infection with methicillinresistant Staphylococcus aureus, for which she was treated with teicoplanin. In addition, one episode of acute rejection was controlled with rabbit antithymocyte globulin beside the standard triple-drug immunosuppression with steroids, mycophenolate mofetil (Cell Cept; Roche, Basel, Switzerland), and cyclosporine A (INN: ciclosporin) (Sandimmune Neoral, Cyclosporin A; Novartis, Basel, Switzerland). Mobilization of the patient and weaning from the respirator were strongly impaired by the patient's fragile condition and poor nutritional status. As a result, she could not be weaned from the respirator until postoperative day 28 and was discharged to her home on day 70 after transplantation. The chest x-ray film showed a perfect adaption of the two lobes in the chest cavity (Fig 1).

Now, 13 months after transplantation, the patient is in excellent physical condition. She has gained $12 \mathrm{~kg}$, and lung function has continuously improved (Fig 2). At arterial blood gas analysis, oxygen tension is $100 \mathrm{~mm} \mathrm{Hg}$ and carbon dioxide tension, $39 \mathrm{~mm} \mathrm{Hg}$.

Discussion. This report supports the feasibility of the splitlung transplantation technique. The only descriptions of this technique so far were reported by Couetil and coworkers, ${ }^{3}$ who performed extensive animal studies before clinical application of the procedure. The example reported here shows that the technique, exactly as it has been described, can now safely be applied by other centers even without their own pre- ceding experimental work. However, considerable experience with cadaveric lobar transplantation is required before this more advanced technique can be attempted. The technique of transplanting split solid organs has been performed in liver transplantation in a large number of mainly pediatric patients ${ }^{5}$ and has become standard in several institutions. Because of the scarcity of small donor lungs, more attention should therefore be given to this technical option by the lung transplantation community.

\section{REFERENCES}

1. Wisser W, Klepetko W, Wekerle T, Laufer G, Stift A, Hiesmayr $\mathrm{M}$, et al. Tailoring of the lung to overcome size disparities in lung transplantation. J Heart Lung Transplant 1996;15:239-42.

2. Starnes VA, Bark ML, Cohen RG. Lobar transplantation: indications, technique and outcome. J Thorac Cardiovasc Surg 1994; 108;403-11.

3. Couetil JP, Tolan MJ, Loulmet DF, Guinvarch A, Chevalier PG, Achkar A, et al. Pulmonary bipartitioning and lobar transplantation: a new approach to donor organ shortage. J Thorac Cardiovasc Surg 1997;113;529-37.

4. Quanjer PH, Tammeling GJ, Cotes JE, Pedersen OF, Peslin R, Yernault JC. Lung volumes and forced ventilatory flows. Eur Respir J Suppl 1993;16:5-40.

5. Goss JA, Schackleton CR, McDiarmid SV, Maggard M, Swenson $\mathrm{K}$, Seu $\mathrm{P}$, et al. Long term results of pediatric liver transplantation: an analysis of 569 transplants. Ann Surg 1998;228:411-20. 